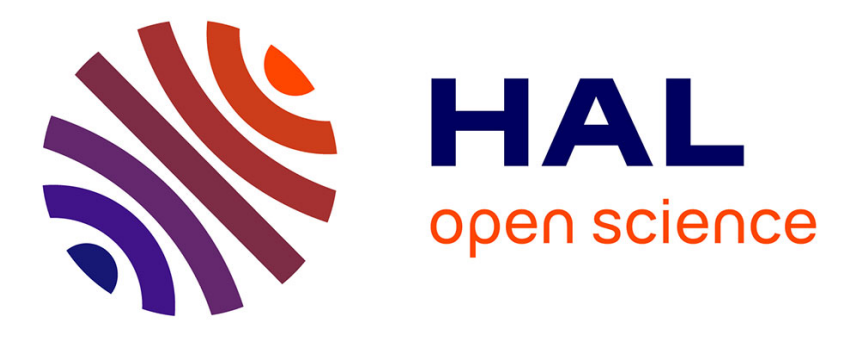

\title{
Design and Development of Orthopedic Implants Through PLM Strategies
}

\author{
Andrea Patricia Murillo Bohórquez, Clara Isabel López Gualdrón, Javier \\ Mauricio Martínez Gómez
}

\section{- To cite this version:}

Andrea Patricia Murillo Bohórquez, Clara Isabel López Gualdrón, Javier Mauricio Martínez Gómez. Design and Development of Orthopedic Implants Through PLM Strategies. 14th IFIP International Conference on Product Lifecycle Management (PLM), Jul 2017, Seville, Spain. pp.231-240, 10.1007/978-3-319-72905-3_21. hal-01764167

\section{HAL Id: hal-01764167 \\ https://hal.inria.fr/hal-01764167}

Submitted on 11 Apr 2018

HAL is a multi-disciplinary open access archive for the deposit and dissemination of scientific research documents, whether they are published or not. The documents may come from teaching and research institutions in France or abroad, or from public or private research centers.
L'archive ouverte pluridisciplinaire HAL, est destinée au dépôt et à la diffusion de documents scientifiques de niveau recherche, publiés ou non, émanant des établissements d'enseignement et de recherche français ou étrangers, des laboratoires publics ou privés.

\section{(c)(1)}

Distributed under a Creative Commons Attribution| 4.0 International License 


\title{
Design and Development of Orthopedic Implants through PLM Strategies
}

\author{
Andrea Patricia Murillo Bohórquez ${ }^{1}$, Clara Isabel López Gualdrón², Javier \\ Mauricio Martínez Gómez ${ }^{3}$ \\ Escuela de Diseño Industrial, Universidad Industrial de Santander, Bucaramanga, Colombia. \\ Andre murillo25@hotmail.com, clalogueuis.edu.co, \\ javimar@uis.edu.co
}

\begin{abstract}
The main research purpose in this work was to propose strategies to reduce uncertainty, setbacks and development times involved into orthopedic implants design process. For research proposal, it was used as reference a manufacturing framework design, based on simulation environments tools and PLM strategies. In addition, this research was carried out to define a model of practices which facilitated process interoperability in osteosynthesis implant development. The model proposed focused on product definition stages and manufacturing as a workflow which defined stages, processes, activities and roles in production of implants with collaborative work scheme in PLM. As part of model execution, a case study was developed in a technology-based company which produces osteosynthesis implants. Finally, the research compared traditional processes in this company with the new model proposed, in order to determine obtained improvements.

Finally, this comparison shows reduction in repetitive operations and uncertainty into the processes. Besides, quality of final design was improved like high precision and time reduction.
\end{abstract}

Keywords: Technologies Integration, Design Process, Manufacturing Design, Medical Device Development.

\section{Introduction}

Medical devices are health care products, and these kind of goods has been becoming one of the most profitable areas in medicine [2], in part at increase in average life expectancy, degenerative diseases [3], musculoskeletal system pathological conditions, trauma caused by accidents (traffic, sports, and domestic) and risky life practices [4]. The expectations of market shared for new product development of orthopedic medical devices is growing up. For health care companies, is an imperative need to improve their capabilities to developing innovative products [1] through design activities integrated in new product development process.

adfa, p. 1, 2011.

(c) Springer-Verlag Berlin Heidelberg 2011 
Epidemiological studies show that more than seventy percent of any trauma cases have required surgery treatment, and usually a fracture also has required to be reduced by ostheosyntesis implant. Hence, an implant must be adapted anatomically to restore as well as possible a broken bone [5]. However, development of orthopedic implants might be complex, because a piece of an anatomical structure must be replaced or reduced, partially or totally [2].

These orthopedic devices require to merging activities performed by CAx software during definition and development process [6]. However, innovation of medical devices in technology-based companies is an intricate process, and require multidisciplinary approaches to knowledge, such as medicine, engineering and design [6]; these sort of products could lack adequate process development, if controls, technology management [7], and regulations were not attended [8]. Likewise, depending on products complexity, difficulties can arise when iteration activities happen, or obtaining a physical product [9]. This landscape is a challenge for organizations that must generate patient-friendly products, and ensure patient safety. Finally, these products must comply with current health regulations and being profitable [2].

Specific design and performance requirements were defined to accelerate innovation and product launching [10]; this approach is known as life product life-cycle management (PLM) and is applied in New Product Development (NPD) process. PLM technologies purpose is to offer managerial tools to improving product development process. PLM is referenced as well as a strategy oriented to provide business solutions. Given these points, project resources and areas like product definition, process integration, people and systems, those were high interested areas for applying this kind of strategies. These strategies are well-timed to articulate goals, data and processes of product development from each department, in order to share information through collaborative approach; in other words, these strategies are aimed more particularly at better organization of product development processes from each department to share the information [11]. Strategies have the ability to address complex products with a large number of technical components, or components developed by different organizational teams [12]]. Also, it is looking for reduce complexity of products, increase productivity in processes, reduce cost and shorten processing times by optimizing workflow [13]. 
CAx tools are a form to integrate some software in a workflow model to create new products. These software tools have been used in production of plastic parts [16], engineering parts [17], and robotics [18]. With these kind of software many companies have achieved outcomes successfully, focusing on product development, manufacturing cycle times and production costs reduction [19].

Through PLM, integration of CAx tools with the intention to improve the accuracy of medical devices is possible, obtaining a significative development time reduction [3] [14] [15], equally drop in uncertainty level that normally is evident in medical devices development process. In effect, practices to improve efficiency in design and manufacturing process were created by incorporating advances in information technology, systematization of product definition and development activities. CAx tools such as Computer Aided Design (CAD) to modeling parts, Computer Aided Manufacturing (CAM) oriented to make or produce components or products, and Computer Aided Engineering (CAE) to verify mechanical behavior of material and quality of the workpiece by simulation techniques; those have been integrated as PLM technologies.

In spite of the important contributions achieved through PLM in areas such as: aero-space [13], aeronautics [20], textiles [11] modular products [21], and productive processes, there are few contributions about PLM in medical sector and orthopedic implants development. Those are oriented on using PLM as a tool only for product management in their economic life [6], or improving biomedical systems, by merging clinical processes and PLM with the intention to increase patient attention quality [22].

In summary, according with the explanation about problems which have been solved through PLM strategies in other sectors, therefore, the authors of this research made a preliminary study using a diagnostic tool [9]. In this diagnosis, weaknesses were identified in areas like business, product and project management, collaboration and integrated workflow. Based on the diagnosis performed, the main purpose of this research was proposing a model of practices by PLM strategies in function to improve osteosynthesis implant design process. The paper is structured as follows: In Section 2 describes the methodology. In Section 3, explains the proposal and main results of case study. Finally in Section 4, the article concludes with a discussion of limitations. 


\section{Methodology}

For present research, an exploratory study was chosen, so methodology was structured according to design thinking (DT) approach. DT is a process for problem-solving oriented to the practice, allowing approaches at product development into the company, and identifying weaknesses related with customized solutions.

In the first stage, researchers applied a diagnostic tool on product lifecycle management with the aim of identify capabilities and weaknesses into the company, specifically in product development. Information was obtained through interviews, which had done to the manager and technical staff. A line of questions were formulated about "which is the problem", "why is being generated and how it affects product development". Also, a field observation was hold in order to checking methodology followed by company.

In second stage, a case study was defined. Obtained data were analyzed about a product manufactured by the company. Times of processes, relationship of contact area between bone and plate, and finally resources required for model implementation.

Finally, in third stage, according to the analysis and previous evaluations, a new workflow was proposed based on PLM strategies, with the aim to develop a design process for osteosynthesis implants. For verification purposes, the new workflow was applied and analyzed by comparative evaluation with the model made by company. The evaluation scope was verifying design solutions physically, comparing times of each process. The accuracy of plate it was verified by measuring the contact area between bone and plate. Once workflow and software tools were defined, PLM strategies through project data management (PDM) were applied. With that in mind, activities for implant development in the case study were integrated.

\section{$3 \quad$ Results}

\subsection{Diagnostic}

The main results obtained from the case study, carried out in the osteosynthesis implant company, according to preliminary analysis, the company's mature capabilities. The four main levels such as: Business, product and pro- 
ject management and the last level collaboration integration are described below.

Business management: New product development has been performed by the company in organized way, based on market supply and competition offers alternatives. There were no collaborative information systems within the organization, so the main software tools (CAD, Office, etc.) were using on independently. The "Know How" of the company resides mainly in people, owing to workers experience, and no common source of knowledge was available inside organization.

Product management: The stages evaluated in the design of a product were focused on conceptual definition, design and detail engineering. Management of documentation which had been generated by each application took as a reference a shared folders system by organization, which had stored their documents manually. It is essential to have a software to allow plans visualization and to facilitate supervision in modifications that has made.

Project management: The project control tools were not found.

Collaboration in integration. Workflow in product design process was lineal and sequential, preventing different user's involvement in creation of technical files, in order to get better changes tracking. Product design and manufacturing departments acted separately, having their own information systems.

The analysis of weaknesses in the company workflow regarding definition process and osteosynthesis implants manufacturing was deployed in Fig. 1. Design process were highlight in blue, manufacturing process in green, production in orange, and finally, problems in red. These problems were presented in obtaining a reference model, for the design of the plate, the product design and the manufacturing processes, by example metal bender and fixture. Designing process involved on these devices has been complex, because it is responsible for generating specific curvatures in the plate and fixing those during the manufacturing processes. Difficulties during manufacturing processes might generate extensive development times, repetitions of activities and material losses. 


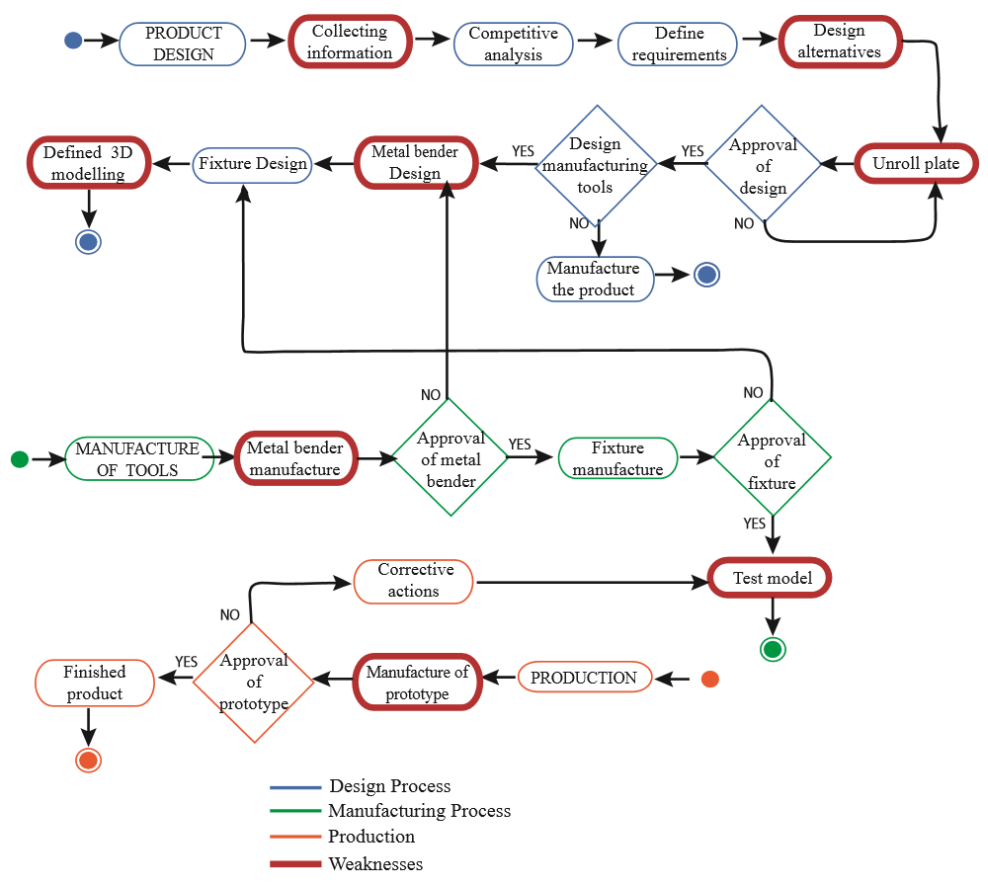

Fig. 1. Company workflow.

\subsection{Case Study}

The case study was carried out in an SME Colombian dedicated to design and manufacture of orthopedic implants like plates, screws and nails. The selection of the case study was defined according company's needs to manufacture a product. Mainly this type of plates implies necessary the design of specialized devices for manufacturing it. Main problem identified was a poor accurate of plate for proximal tibia at bone, which led to duplicate process and prolong times for product development. Table 1 shows a reference SWOT matrix, identifying weaknesses, opportunities, and threats from the company.

Table 1. SWOT matrix

\begin{tabular}{|l|l|}
\hline \multicolumn{1}{|c|}{ STRENGTHS } & \multicolumn{1}{c|}{ WEAKNESSES } \\
\hline - Novelty or improvements to the prod- & - Absence of virtual models of \\
ucts & $\begin{array}{l}\text { bones } \\
\text { - Make efficient the design process }\end{array}$ \\
& $\begin{array}{l}\text { Realization of unnecessary pro- } \\
\text { cesses }\end{array}$ \\
\hline
\end{tabular}




\begin{tabular}{|c|l|}
\hline & $\begin{array}{l}\text { - They do not follow the method- } \\
\text { ology } \\
\text { - Absence of CAD files } \\
\text { - Information management }\end{array}$ \\
\hline \multicolumn{1}{|c|}{ OPPORTUNITIES } & \multicolumn{1}{c|}{ THREATS } \\
\hline $\begin{array}{l}\text { - Knowledge and management of the } \\
\text { existing production environment }\end{array}$ & $\begin{array}{l}\text { - Low costs of imported products } \\
\text { - Knowledge management }\end{array}$ \\
\hline
\end{tabular}

\subsection{New Workflow}

Workflow defined for this research was structured in four stages. New activities were integrated for testing a piece quality. The first one consisted on obtaining 3D virtual model by using a scanner and reverse engineering techniques to get a bone reference. The second one, virtual design of the plate and manufacturing devices were modeled using CAD technology. In the third stage, Computer Aided Engineering CAE was applied through simulations to virtual verification of plate performed by finite element analysis and virtual simulation of the bending process. Finally, in the fourth stage, physical verification was carried out, making a 3D printed of the designed plate. New integrated workflow system where shown in Fig. 2.

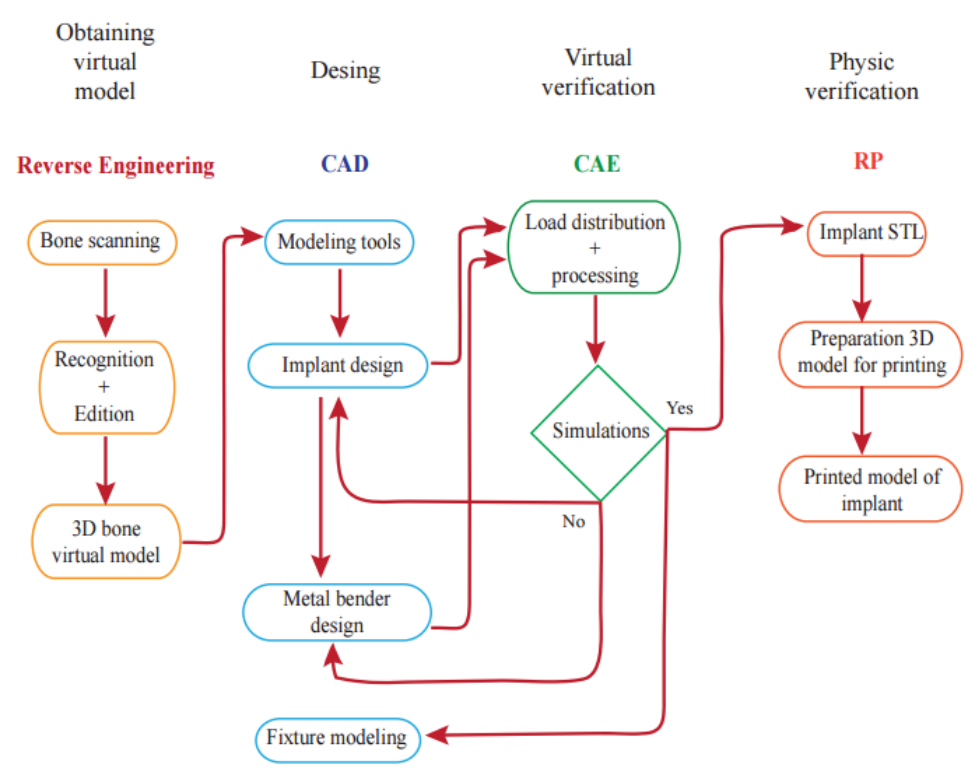

Fig. 2. New integrated workflow system 
Differences between obtained data with the new design process defined by integrated workflow system and the company process was due in part, because new workflow was based on virtual and simulation environments, instead of manual processes. These new design processes also allowed biomechanical analyzes that reduced iterations and uncertainties during the plate development process. As new PLM technologies generated more advantages over older technologies. However, this change implies updating design area in the company with other processes, tools and skills.

To evaluate fulfillment of the objectives set out in this research, a comparative evaluation was made between traditional model developed in the company, and the workflow proposed according to PLM strategies. Additionally, this study evaluated times for each activity performed by company process and it was compared them with times and activities of workflow proposed in Table 2. This comparison has showed a decrease in development times, and also decrease in amount of resources demanded by workflow proposed, compared with processes and activities that company currently does.

Likewise, the quality of practices applied to get plate design was verified through measuring bone to plate contact. Hence, data from areas of contact were obtained to plate made by company process and plate made by PLM workflow and these data were compared.

Table 2. Comparison between the traditional company process and the workflow proposed

\begin{tabular}{|l|c|c|}
\hline & Company Process & PLM Workflow \\
\hline Activity & Time & Time \\
\hline Obtaining virtual model & $02: 00$ & $00: 15$ \\
\hline Implant design & $128: 30$ & $11: 30$ \\
\hline Unroll plate & $01: 00$ & ---- \\
\hline Biomechanical analysis of plate & ---- & $00: 50$ \\
\hline Devices design (fixture and metal bender) & $100: 00$ & $03: 05$ \\
\hline Biomechanical analysis of metal bender & ---- & $01: 20$ \\
\hline Test model & $03: 00$ & $01: 15$ \\
\hline Total (Hours: minutes) & $\mathbf{2 3 4 : 3 0}$ & $\mathbf{1 8 : 2 5}$ \\
\hline
\end{tabular}


Table 3 showed that with integration of PLM technologies process, having the geometry required and adjusted was more accurate. This was evident with an increase in the contact area, respect to the company process, which results were $16 \%$ in longitudinal section and $2,5 \%$ in the cross section.

Table 3. Comparison of areas of contact between bone and plate

\begin{tabular}{|l|c|c|c|}
\hline Variable & Company Process & $\begin{array}{c}\text { Workflow } \\
\text { Proposed }\end{array}$ & $\begin{array}{c}\text { Percent areas } \\
\text { of contact } \\
\text { incremented }\end{array}$ \\
\hline $\begin{array}{l}\text { Contact longitudinal } \\
\text { section area }\end{array}$ & $123,85 \mathrm{~mm}^{2}$ & $143,85 \mathrm{~mm}^{2}$ & $16 \%$ \\
\hline $\begin{array}{l}\text { Contact cross } \\
\text { section area }\end{array}$ & $23,67 \mathrm{~mm}^{2}$ & $24,27 \mathrm{~mm}^{2}$ & $2,5 \%$ \\
\hline
\end{tabular}

Finally, in Fig. 3, information about activities and roles of the product development integrated on PDM was presented. This PLM strategy improved interoperability between design and manufacturing departments, reducing development times and improved process management.

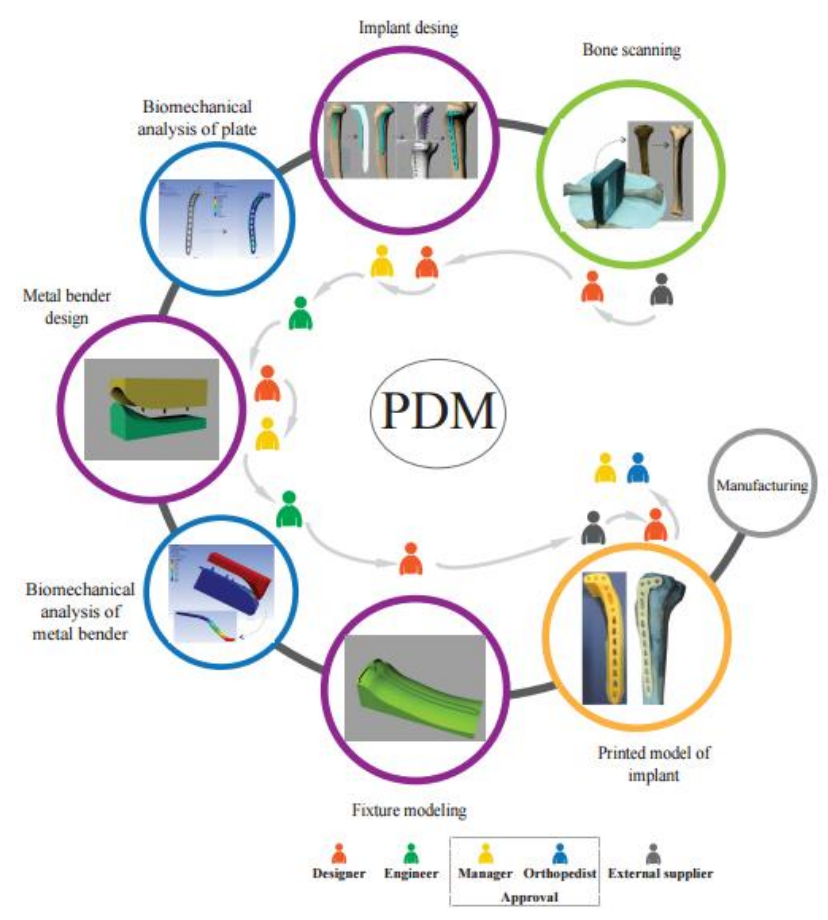

Fig. 3. PDM system. 


\section{Conclusions}

The executed process had allowed a proposed workflow in design process of orthopedic implants. This process was developed with a methodological approach based on PLM strategies and scientific literature [8-13]. Outputs showed in time decrease were about approximately $92 \%$ in design process, according to company process showed in Table 2 . In addition, new workflow evidenced that communication and information ex-change between design and manufacturing departments was improved through PDM strategies applied in design and manufacturing process, obtaining collaboration and integration for those areas.

Workflow implementation not generated economic impacts, because the study case was conducted through a theoretical assessment. Given the scope of the study, it was not contemplated deploying workflow in the company, but at the same time, some proposed strategies were implemented. The new single workflow was taken into account for the development of orthopedic plates. Other products offering by company such as screws and nails have different development processes, which do not require integration of proposed technologies.

Proposed workflow will by PLM strategies help to prevent possible design mistakes by virtual and simulation environments, involving verification during all stages. These tools are used to make decisions before product manufacturing and market release. According to software tools applied in the workflow, as reverse engineering and biomechanical analysis, those allow to get more accurately geometries, design parts, reducing development times, reiterative manual activities, and improving management resource. Finally, use of PLM strategies facilitated manufacturing processes into the company, integrating organizational structure, stages of development, work activities, roles and controls. The workflow proposed in this study proved to have better results in product definition stage, evidenced Fig. 2, as well as an enhancement in control process and effectiveness.

\section{References}

[1] Global Market Insights, "Orthopedic Devices Market Size, Trends," 2017.

[2] W. Khan, M. Jaffe, and A. Domb, "Implantable Medical Devices," in Advances in Delivery Science and Technology, 2014, pp. 33-59.

[3] M. Cronskär, "on Customization of Orthopedic Implants- From Design and Additive 
Manufacturing To Implementation," 2014.

[4] C. Radu and I. Roşca, "Some contributions to the design of osteosynthesis implants," Est. J. Eng., vol. 15, no. 2, p. 121, 2009.

[5] T. R. Kucklick, The Medical Device R \& D Handbook. 2006.

[6] A. Díaz Lantada, Handbook on Advanced Design and Manufacturing Technologies for Biomedical Devices. Springer, 2013.

[7] Y. Songkajorn and N. Thawesaengskulthai, "Medical Device Innovation Development Process," Int. J. Innov. Technol. Manag., vol. 11, no. 4, p. 1450027, 2014.

[8] L. a. Medina, G. E. Okudan, and R. a. Wysk, "Supporting medical device development: a standard product design process model," J. Eng. Des., vol. 24, no. 2, pp. 83-119, 2013.

[9] Fundación Prodintec, "Herramienta de Autodiagnóstico de la Gestión del Ciclo de Vida del Producto," 2010.

[10] V. Gecevska, P. Chiabert, Z. Anisic, F. Lombard, and F. Cus, "Product lifecycle management through innovative and competitive business environment," J. Ind. Eng. Manag., vol. 3, no. 2, pp. 323-336, 2010.

[11] F. Segonds, F. Mantelet, J. Nelson, and S. Gaillard, "Proposition of a PLM tool to support textile design: A case study applied to the definition of the early stages of design requirements," Comput. Ind., vol. 66, pp. 21-30, 2015.

[12] H. P. L. Bruun, N. H. Mortensen, U. Harlou, M. Wörösch, and M. Proschowsky, "PLM system support for modular product development," Comput. Ind., vol. 67, pp. 97111, 2015.

[13] F. Mas, R. Arista, M. Oliva, B. Hiebert, I. Gilkerson, and J. Rios, "A Review of PLM Impact on US and EU Aerospace Industry," Procedia Eng., vol. 132, pp. 1053-1060, 2015.

[14] J. B. Pietzsch and M. L. Paté-cornell, "Stage-Gate Process for the Development of Medical Devices," J. Med. Device., 2009.

[15] S. K. Chandrasegaran, K. Ramani, R. D. Sriram, I. Horváth, A. Bernard, R. F. Harik, and W. Gao, "The evolution, challenges, and future of knowledge representation in product design systems," Comput. Des., vol. 45, no. 2, pp. 204-228, Feb. 2013.

[16] J. M. Mercado-Colmenero, M. A. R. Paramio, J. M. Perez-Garcia, and C. MartinDoñate, "A new hybrid method for demoldability analysis of discrete geometries," Comput. Des., vol. 80, pp. 43-60, 2016.

[17] Z. Xia, Q. Wang, Y. Wang, and C. Yu, "A CAD/CAE incorporate software framework using a unified representation architecture," Adv. Eng. Softw., vol. 87, pp. 68-85, 2015.

[18] K. Park, Y. S. Kim, C. S. Kim, and H. J. Park, "Integrated application of CAD/CAM/CAE and RP for rapid development of a humanoid biped robot," J. Mater. Process. Technol., vol. 187, pp. 609-613, 2007.

[19] G. Lyu, X. Chu, and D. Xue, "Product modeling from knowledge, distributed computing and lifecycle perspectives: A literature review," Comput. Ind., vol. 84, pp. 1-13, 2017.

[20] F. Mas, M. Oliva, J. Ríos, A. Gómez, V. Olmos, and J. A. García, “PLM Based Approach to the Industrialization of Aeronautical Assemblies," Procedia Eng., vol. 132, pp. 1045-1052, 2015. 
[21] H. P. L. Bruun, N. H. Mortensen, U. Harlou, M. Wörösch, and M. Proschowsky, "PLM system support for modular product development," Comput. Ind., vol. 67, pp. 97111, 2015.

[22] A. S. López, C. Del Valle, M. J. Escalona, V. Lee, and M. Goto, "Patient Lifecycle Management: An Approach for Clinical Processes," Bioinforma. Biomed. Eng. - Third Int. Conf. \{IWBBIO\} 2015, Granada, Spain, April 15-17, 2015. Proceedings, Part $\{I I\}$, vol. 9044, pp. 694-700, 2015. 